\title{
Stressincontinentie bij mannen: prospectieve dataregistratie en studies dringend nodig
}

\author{
Frank M. J. Martens · Erik B. Cornel
}

Geaccepteerd op: 5 juli 2021 / Published online: 9 augustus 2021

(C) The Author(s) 2021

\begin{abstract}
Samenvatting In dit opiniestuk proberen de auteurs de volgende vraag te beantwoorden: 'stressincontinentie bij mannen: waarom we prospectieve studies nodig hebben'. We leggen uit dat een jarenlang bestaande gouden standaard als operatieve oplossing, namelijk de sfincterprothese, en overhaaste introductie van allerlei andere chirurgische oplossingen zoals de verschillende male slings en de verschillende indicaties voor deze ingrepen, randomized controlled trials bemoeilijken. We benadrukken dat naar onze mening anamnese en resultaten op een gestandaardiseerde manier moeten plaatsvinden. Alleen op die manier zal het in de toekomst mogelijk worden onderzoeksresultaten te vergelijken en een uitspraak te doen over wanneer welke incontinentieoperatie geïndiceerd is en wellicht ook nog door wie in welk centrum. Het is niet de bedoeling een klinkklare oplossing voor de toekomst te geven, maar wel om de discussie te verlevendigen.
\end{abstract}

Trefwoorden mannelijke stressincontinentie $\cdot$ male sling - sfincterprothese

\section{Male stress urinary incontinence: prospective data registry and studies are urgently required}

\footnotetext{
Abstract In this opinion article, the authors attempt to answer the question: 'stress incontinence in men: why we need prospective studies'. We explain that having a gold standard as an operative solution for many years: the sphincter prosthesis, hasty introductions of all kinds of other surgical solutions such as

\section{dr. F. M. J. Martens ( $₫)$}

afdeling Urologie, Radboudumc, Nijmegen, Nederland

frank.martens@radboudumc.nl

dr. E. B. Cornel

afdeling Urologie, ZGT, Hengelo, Nederland
}

different male slings and the different indications for these procedures, make randomized controlled trials more difficult. We emphasize that in our opinion anamnesis and results should be done in a standardized manner. Only in this way will it be possible in the future to compare results and to make a statement about when which incontinence surgery is indicated and perhaps also by whom in which center. It's not the purpose to describe a clear solution how to proceed in the future, but it is to activate a discussion about it.

Keywords male stress incontinence - male sling · sphincter prosthesis

\section{Introductie}

Stressincontinentie bij de man komt met name voor na een radicale prostatectomie vanwege prostaatcarcinoom. Na een TURP komt een zeer milde vorm van stressincontinentie voor bij minder dan $1-2 \%$ van de mannen [1]. De incidentie van postradicale prostatectomie-incontinentie varieert sterk (5-25\%), afhankelijk van de ervaring van de operateur en of de operatie plaatsvond in een hoog- of laagvolumecentrum [2].

In dit artikel proberen de auteurs de vraag te beantwoorden: 'stress incontinentie bij mannen: waarom hebben we prospectieve studies nodig?, waarbij zal worden ingegaan op onderzoek en implementatie van onder andere de sfincterprothese en de male sling.

\section{De AMS800-sfincterprothese}

Als alle conservatieve therapieën voor stressincontinentie na een radicale prostatectomie geen resultaat hebben gehad, is een chirurgische oplossing de enige mogelijkheid. De sfincterprothese heeft haar nut be- 
wezen sinds de introductie ervan in 1972 door Brantley Scott; sinds 1983 wordt de AMS800 het vaakst toegepast [3]. In een recente review van de resultaten en complicaties van de AMS800 wordt een gemiddeld droog (geen verband) percentage van $42 \%$ gezien (range 4-86) [4]. Sociaal continent (geen of 1 pad) is $79 \%$ (range 61-100), waarbij onduidelijk is hoe nat die ene pad mag zijn. Het risico op heroperatie in 10 jaar is met $26 \%$ (range 15-45) aanzienlijk. Enerzijds worden heroperaties beschouwd als een gevolg van implantatie van een mechanische oplossing die een beperkte levensduur heeft, anderzijds zijn de complicaties - atrofie en infectie - ook een belangrijke aanleiding. Net als bij de radicale prostatectomie zijn de resultaten en complicaties van de implantatieprocedure van de AMS800 sterk afhankelijk van de operateur [4, 5]. Desalniettemin is een sfincterprothese, waaronder de AMS800, nog steeds de gouden standaard [4, 5]. Aangezien het jarenlang de enige operatieve mogelijkheid was voor stressincontinentie na radicale prostatectomie is de noodzaak tot prospectief onderzoek niet echt aanwezig geweest en komen de meeste resultaten uit retrospectieve single-centerstudies.

\section{Male sling}

In 2007 werd door Rehder en Gozzi de Advance male sling geïntroduceerd [6]. Kenmerkend voor de, in onze ogen, commerciële haast was een summiere publicatie met 10 kadaverpatiënten en de resultaten van slechts 10 mannen die een prototype van deze sling geïmplanteerd kregen [6]. Op basis van deze eerste studie werd, mede dankzij de destijds geldende regels van de Nederlandse en internationale overheidsinstanties, de introductie van een male sling die zijn effectiviteit nog moest bewijzen op grote schaal geïntroduceerd. Vanwege de summiere wetenschappelijk opvolging hebben Elzevier en Cornel bij aanvang van hun implantaties de patiënten prospectief vervolgd.

In hun studie van 36 patiënten die in een jaar tijd werden geopereerd, werd met behulp van vragenlijsten en een 24 uurs pad-test de effecten van de implantatie van de advance male sling op de incontinentie gemeten [7]. Daarnaast werden prospectief de complicaties bijgehouden. De resultaten waren ontluisterend. Slechts bij 7\% van de patiënten werd volledige continentie bereikt. Dit deed een heftige wetenschappelijk discussie ontvlammen, met vele ingezonden brieven. Zoals het vaker gaat met negatieve publicaties, werden de resultaten terzijde geschoven. In 2010 kwam een 'verbeterde' versie van de Advance male sling (Advance XP) op de markt, waarna in hoog tempo allerlei andere male slings in de markt werden gezet, allemaal zonder enig bewijs van effectiviteit. Daarnaast werden surrogaat uitkomstmaten geïntroduceerd, zoals de 'sociale continentie' en succes betekent 'droog of meer dan $50 \%$ verbetering van incontinentie'. Het is de vraag of je van een succes kunt spreken als je van $250 \mathrm{ml}$ verlies per dag nog steeds
$100 \mathrm{ml}$ verlies per 24 uur hebt. Door deze studies, die in de eerste jaren na de introductie gedaan zijn, werd wel duidelijk dat er subgroepen patiënten waren bij wie implantatie van de male sling tot slechte resultaten leidde. Deze groep bestond uit patiënten die een salvage radiotherapeutische behandeling ondergaan hadden, zeer fors incontinent waren en ook uit patiënten met een sfincterdeficiëntie. Dit slechte resultaat, in combinatie met verschillende definities van inclusie, de mate van incontinentie en de uiteenlopende definiëring van (surrogaat) uitkomstmaten maken het erg moeilijk om een vergelijking te maken tussen de resultaten van de diverse typen maleslingoperaties, bulktherapieën, ProACT-ballonnen en verschillende typen sfincterprotheses enerzijds en de uitkomsten van een AMS800-sfincterprothese (de huidige gouden standaard) anderzijds.

Het resultaat van dit alles is dat de level of evidence voor de verschillende incontinentieoperaties voor de man laag is en dat de aanbevelingen in richtlijnen mede stoelen op expert opinion. Beoordeling voor vergoeding door de Nederlandse zorgautoriteiten wordt door de matige wetenschappelijke onderbouwing ook bemoeilijkt.

Recent heeft Cornel daarom de middellange-termijnresultaten gepubliceerd van zijn onderzoek naar de Argus-T single incision procedure; een rapportage over 78 patiënten $(69 \pm 6$ jaar $)$ met een preoperatief 24 uursverlies van mediaan 212 (interkwartielrange 75-385) g. Direct postoperatief was $64 \%$ van de patiënten compleet droog, bij $79 \%$ van de patiënten verbeterde het urineverlies $>90 \%$ en bij $92 \%>50 \%$. Na 5 jaar follow-up was dit respectievelijk 53\%, $72 \%$ en $80 \%$ [8].

\section{Hoe nu verder?}

\section{Structurele oplossing}

Naar onze mening zal dit probleem structureel opgelost dienen te worden.

Allereerst dient een goede evaluatie van mannelijk incontinentie plaats te vinden. Conform ICS-richtlijnen zal een zorgvuldige anamnese moeten plaatsvinden waaruit onder andere duidelijk wordt: wat de oorzaak van de incontinentie is (robotgeassisteerde/ laparoscopische/open prostatectomie, TURP of anderszins), of er radiotherapie op de genitale regio is verricht, en of er voorgaande incontinentiebehandelingen zijn geweest [9]. Een gevalideerde vragenlijst, bijvoorbeeld de ICIQ-UI-SF, zal zowel voor de ingreep als naderhand moeten worden afgenomen om een objectieve maat te hebben van de patiëntperceptie. Daarnaast zal in plaats van het aantal verbanden per dag een betere meting van incontinentie moeten plaatsvinden: de 24 uurs pad-test zal - wanneer deze een aantal dagen wordt bijgehouden - een reëel beeld geven van de mate van incontinentie per 24 uur. Misschien is die 24 uurs pad-test de meest 
objectieve en minst surrogaatmeting die we hebben. Echter, ook deze variabele blijft afhankelijk van de mate van inspanning op de betreffende dagen en dus de vraag of we naar een gemiddelde 24 uurs-incontinentiegewicht over meerdere dagen moeten kijken (met range), of naar het maximale of de mediane gewicht.

Ten tweede zal een beoordeling van het resultaat moeten plaatsvinden die wordt gekenmerkt door het adagio 'meten is weten'. Daarom zullen op vaste tijdstippen na de incontinentiechirurgie, bijvoorbeeld jaarlijks, de resultaten moeten worden gemonitord met objectieve uitkomstmaten. Daarbij zal een gedegen complicatieregistratie plaats moeten vinden. Gezien de mate van individuele verschillen binnen deze groep patiënten (de hoeveelheid incontinentie, wel/geen radiotherapie, wel/geen voorgaande incontinentiebehandelingen) dienen resultaten niet alleen als groep, maar ook per patiënt bijgehouden te worden. Dit geeft mogelijk een beter beeld dan de mediane verbetering per groep. Je wilt weten wie postoperatief droog is en wie niet, met name om ook de preoperatieve voorspellende factoren te bepalen. Beoordeling op objectieve uitkomsten dus.

Daarnaast dienen we de patiëntperceptie niet uit het oog te verliezen: PROMS zullen ook belangrijk zijn. Een patiënt die meer dan een liter urine per 24 uur verliest en postoperatief nog maar $100 \mathrm{~g}$ per 24 uur zal wellicht meer tevreden zijn dan de patiënt die van 200 g naar 20 g gaat. Beide een reductie van $90 \%$, maar is de patiëntperceptie ook hetzelfde?

Indien anamnese en resultaten op een gestandaardiseerde manier plaatsvinden, zal het in de toekomst mogelijk worden resultaten te vergelijken. Wellicht kan dan een uitspraak gedaan worden over wanneer welke incontinentieoperatie geïndiceerd is en wellicht ook nog door wie in welk centrum.

\section{RCT's voor mannelijke incontinentie}

Recent is de Master trial in European Urology gepubliceerd [10]. Dit is een eerste poging om een gerandomiseerd vergelijkende studie op te zetten tussen de sfincterprothese (AUS) enerzijds en de male sling anderzijds. Er deden maar liefst 27 ziekenhuizen mee, waar in vier jaar tijd in totaal 380 patiënten gerandomiseerd werden naar een male-slingoperatie of een AUS. Het betrof een non-inferiority trial en de primaire uitkomstmaat was patiëntgerapporteerde incontinentie op basis van twee items uit de gevalideerde ICIQ-UI-SF. Secondaire uitkomstmaten waren operatieve details, complicaties en patiëntgerapporteerde metingen. De resultaten van deze trial laten geen verschil zien tussen AUS of male sling; respectievelijk 13 en $16 \%$ van de geopereerde patiënten waren droog na de incontinentiechirurgie.

Om de resultaten en conclusies van dit stukje meesterwerk goed te kunnen interpreteren, is een aantal kritische kanttekeningen op zijn plaats. Allereerst, de inclusiecriteria zijn veel te breed genomen waardoor de twee groepen niet goed met elkaar te vergelijken zijn. Circa $25 \%$ van het totaal aantal geïncludeerde patiënten had stressincontinentie na TURP of had na de prostaatkankeroperatie salvageradiotherapie gehad. Dit zijn nou juist de mannen bij wie al voor 2014 duidelijk was dat de resultaten na een maleslingoperatie belabberd zijn. Ten tweede, de inclusieperiode was maar liefst vier jaar, en met 27 centra voor 380 patiënten is het de vraag wat het volume per centrum is en dus de resultaten per centrum, dan wel bias doordat er relatief weinig patiënten van de deelnemende centra werden geïncludeerd. Ten derde moet de competentie van operateurs in ogenschouw worden genomen. De AUS-techniek viel binnen de competenties van alle chirurgen, maar de techniek om een male sling aan te brengen niet. De operateurs die hier geen ervaring mee hadden, werden opgeleid door een ervaren operateur totdat ze geschikt werden geacht. Dit is in onze ogen wel een hele magere definitie van competent. Ten vierde, meten is weten, en de in onze ogen belangrijke 24 uurs pad-test was bij slechts $84 \%$ van de patiënten bij inclusie bekend. Tijdens de follow-up van één jaar was dit percentage gedaald naar $23 \%$ in de AUS-groep en $26 \%$ in de groep die een male sling kreeg.

\section{Wat kunnen we in de toekomst nog verwachten?}

Momenteel nemen verscheidene Nederlandse centra deel aan de SATURN-studie van de EAU Research Foundation, die in meerdere Europese centra loopt. Deze studie betreft een registratie van alle implantaten die bij mannen met stressincontinentie binnen een centrum worden toegepast. De komende jaren hopen we hier de eerste data van te zien. Of deze data de vraag wat te doen, wanneer en bij welke patiënt, kan beantwoorden, is gezien de inclusie van grotendeels sfincterprotheses en de variëteit aan slings nog de vraag. Voor de Nederlandse situatie zouden wij het wenselijk vinden om samen met de functioneel urologen in Nederland (via de WEFURU) tot een consensus ten aanzien van de follow-upstrategie na implantatie te komen. Dit zou de resultaten van de beschikbare middelen binnen Nederland vergelijkbaar maken. De DRES-M-studie die voor dit doel mede was opgezet, is helaas door gebrek aan financiering van onder andere ZONMW niet van de grond gekomen. De registratie van implantaten binnen een database van de NVU is dit jaar voor een aantal implantaten (voor mannelijke stressincontinentie vooralsnog alleen de male slings) gestart als pilot. Registratie aan de bron, automatisch vanuit het patiëntendossier, is hierbij het streven; enerzijds voor het verkrijgen van nauwkeurige data, anderzijds om dubbele registratielast te voorkomen. Helaas is registratie aan de bron op dit moment nog niet mogelijk. Elke start is moeilijk, extra (handmatige) registraties een last. Echter, als de registratie goed gaat verlopen en we consensus over de follow- 
up kunnen verkrijgen, kunnen we er op termijn ook de vruchten van plukken: onze eigen praktijk evalueren en verbeteren, en patiënten naar de optimale therapie leiden.

\section{Conclusie}

De behandeling van mannen met stressincontinentie is complex, mede doordat het aantal implantaatmogelijkheden en -varianten een hoge vlucht heeft genomen. Is het praktisch wel mogelijk om de vraag 'What's best for which patient' beantwoord te krijgen? Moeten we ons niet veel meer richten op het 'What can be the optimal result at which risk in this patient when I apply a specific prothesis?' Een randomized controlled trial met inclusie van alle varianten, zowel van implantaten als van patiëntgroepen, is praktisch onmogelijk. Prospectieve data met harde eindpunten zijn wenselijk.

Open Access This article is distributed under the terms of the Creative Commons Attribution 4.0 International License (http://creativecommons.org/licenses/by/4.0/), which permits unrestricted use, distribution, and reproduction in any medium, provided you give appropriate credit to the original author(s) and the source, provide a link to the Creative Commons license, and indicate if changes were made.

\section{Literatuur}

1. Bosch R. Richtlijn urine-incontinentie voor de tweede- en derdelijnszorg. Versie2.0. Utrecht: NVU;2014.
2. Nam RK, Herschorn S, Loblaw DA, et al. Population based study of long-term rates of surgery for urinaryincontinence after radical prostatectomy for prostate cancer. J Urol. 2012;188(2):502-6.

3. Fishman IJ, Shabsigg R, Scott FB. Experience with the artificial urinary sphincter model AS800 in 148 patients. JUrol. 1989;141(2):307-10.

4. AaFvander, DrakeMJ, Kasyan GR, etal. Theartificialurinary sphincter after a quarter of a century: a critical systematic review of its use in male non-neurogenic incontinence. Eur Urol. 2013;63(4):681-9.

5. Burkhard FC, Bosch JLHR, Cruz F, et al. EAU guidelines. Arnhem: EAU; 2020.

6. Rehder P, Gozzi C. Transobturator sling suspension for male urinary incontinence including post-radical prostatectomy. Eur Urol. 2007;52(3):860-6.

7. CornelEB, Elzevier HW, Putter H. Can advance transobturator sling suspension cure male urinary postoperative stress incontinence? J Urol. 2010;183(4):1459-63.

8. Casteleijn NF, Cornel EB. Argus-T adjustable male sling: a follow-up study on urinary incontinence and patient's satisfaction. Neurourol Urodyn. 2021;40(3):802-9.

9. Herschorn S, Bruschini H, Comiter C, et al. Surgical treatment of stress incontinence in men. Neurourol Urodyn. 2010;29(1):179-90.

10. Abrams P, Constable LD, Cooper D, et al. Outcomes of a noninferiority randomised controlled trial of surgery for men with urodynamic stress incontinence after prostate surgery (MASTER). Eur Urol. 2021;79(6):812-23.

dr. Frank M.J. Martens, uroloog

dr. Erik B. Cornel, uroloog 


\title{
Hier staat een advertentie.
}

\author{
$c$ bohn

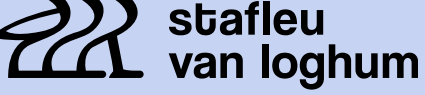 \\ Springer Media
}

Houten 2021 